May 5, 4 a.m., near Grossenhain, Saxony.

, 5, Island of Rügen, on the Baltic.

," 6, near Freiberg, Saxony.

, 6, near Königstein, Saxony.

" 6, near Rendsburg, Holstein.

," 7, Reichenau, Saxony.

, 7, near Soldin, Brandenburg, Prussia.

, 7, Palczyn, Posen, Prussia.

, 7, near Leipzig, Saxony.

Royal Zoological Museum, Dresden, May 12

\section{"Coral Formations."}

IN a recent paper read before the Royal Society of Edinburgh, I have pointed out the importance of taking into consideration the molecular condition of carbonate of lime in relation to its solubility in sea-water.

The (tabulated) results of an exhaustive series of tests (see NATURE, vol. xxxvii. p 605) show in a striking manner this difference between the crystalline (or massive) and the amorphous conditions of that body.

In Table II. the amount of carbonate of lime taken up by seawater from decomposing shell-fish is shown to be very great, the clear newly filtered solution giving $0: 384$ grammes per litre (other determinations since made giving still higher results); this is due no doubt to the formation of carbonic acid, the result of the oxidation of the organic matter in the putrefying mass.

The clear (foul-smelling) liquid on standing exposed to the air rapidly decomposes, ammoniacal salts being formed; and a great portion of the amorphous carbonate of lime which was dissolved during the first stages of putrefaction is thrown out of solution and deposited in a crystalline and practically nearly insoluble form.

This may be due to the los; of carbonic acid, or its combination with ammonia, produced during decomposition of nitrogenous organic matter ; or to the well-known action certain salts of ammonia (especially the carbonate) exert in degrading the solubility of carbonate of lime in water; but the result so produced, I think, meets all the objections Mr. T. Mellard Reade brings forward against the solution theory, which is Dr. Murray's explanation of the formation of coral lagoons.

Again, when a clear saturated solution of amorphous carbonate of lime in sea-water (see Table II., $a$ and $b$ ) is allowed to stand for a few hours at ordinary temperatures, the solution becomes turbid and ultimately throws out in a crystalline condition a considerable proportion of the carbonate of lime it held in solution.

Dr. Murray, in a paper on "Structure, Origin, and Distribution of Coral Reefs, \&c.," read before the Royal Institution, London, on March 16, refers to this change of condition as follows:-

"The whole of a coral reef is permeated with sea-water like a sponge; as this sea-water is but slowly changed in the interior parts it becomes saturated, and a deposition of crystalline carbonate of lime frequently takes place among the interstices of the co:als and coral debris."

These facts seem to me quite sufficient to account for the formation of coral lagoons by the more rapid solution of the amorphous form of carbonate of lime, found in dead and decom. posing corals. At the same time other deposits are preserved from wholesale solution by the change in the molecular condition which carbonate of lime undergoes, - always the after result of solution.

I need not here refer to other influences at work in maintaining the balance of absorption and secretion of lime salts in the ocean, because I consider the difference in solubility of various forms which carbonate of lime assumes equally accounts for the formation of lagoons and the preservation of coral reefs and shell beds or banks.

Royston, Granton, Edinburgh, May I4. ROBERT IRVINE.

\section{Aurora Borealis.}

THE aurora borealis was visible here on Sunday night, May 6. We have difficulty in identifying it in this neighbourhood without spectroscopic aid, because the lights of Liverpool and its suburbs extend over the eastern horizon, and the sky to the north-east and north is filled with a glow from Bootle and
Birkenhead, these several lights often giving, with clouds of varying height, effects resembling northern lights.

On Sunday night, at 1.30 , the brightness in the north-western sky was not to be mistaken ; and shortly before 2 o'clock a curved bluish-white beam-two brilliant sides inclosing a still brighter rounded angle of about $70^{\circ}$ - shot up from the west, the apex coming first, and attaining a height of $60^{\circ}$, the sides there being about $\frac{1}{8}^{\circ}$ broad ; the extremities of the sides, $1^{\circ}$ broad, touching the horizon in the north-north-west and south-southeast. This beautiful beam remained a few seconds, then went as it came, the apex disappearing last. The general phenomenon seemed to increase in brightness, but subsequent observations show that it could not then be satisfactorily distinguished from the early dawn and reflected lights.

Rock Ferry, May II.

\section{Weight and Mass.}

THE weight of a body is the quantity which is measured out by the operation of weighing. To weigh a body it is placed in one of the scales of a balance, and equilibrated by standard weights formed of lumps of metal called pounds, hundredweights, tons, \&c., or kilogrammes in the metric system; and the sum of these weights is (pace Mr. R. E. Baynes) called the weight of the body.

The mathematician may now call this quantity, if he likes, the mass of the body; but the world at large uses the word zveight, with the advantage of having the corresponding verb "to weigh," which the substantive "mass" does not possess: we are not yet accustomed to speak of a body "massing" IOO tons. The numerous circumlocutions to express one single idea in Prof. MacGregor's examples arise from the want of the verb "to mass."

The "extraordinary and peculiar" language is, then, that of the elementary text-books of Mechanics, which tell us that the weight of a body is the force with which it is attracted by the earth (Lodge, "Elementary Mechanics," p. 66).

It is true, as Sir Philip Magnus points out in his "Mechanics," $\S 46$, that the word weight is made to do double duty, sometimes standing for force and sometimes for mass; and that these two significations must be carefully distinguished.

But the "ordinary he or she" would no more accept the "pull or heft required to lift a body" as a correct measure of the weight, than the Red Indian of to-day would accept the weight of the Hudson Bay factor's fist as one pound.

The theorist must then exert his ingenuity to invent a new word to express the force idea, to associate with the word mass, already invented by him ; but to attempt to restrict the meaning of the word weight in a manner not usual in ordinary language can only lead to confusion. In any engineering, chemical, or ordinary journal we shall always find weight used in the sense of mass, as defined in the text-books of elementary dynamics; and even in these treatises we shall find in the parts on Statics the word reeight used in its ordinary sense. For instance, on p. I96 of Dr. Lodge's " Mechanics," we find, Ex. 10, " A mass of wood (sp. gr. 0*6) is counterpoised by 105 correct grammes of iron (sp. gr. 7.5); find the mass of the wood (or its true weight in vacuo)."

Sometimes it is not possible to employ the balance to estimate the weight (or mass) of a body; as, for instance, when the chemist evolves a certain weight of hydrogen in a chemical combination, when the artillerist speaks of a gun weighing I Io tons, and when the astronomer "weighs the earth,"-in such cases the weight or mass, whichever it is called, is calculated as the product of the volume and the density: determine for example the weight of 1000 cubic feet of steel. The weight $\mathrm{W}$ (or mass $\mathrm{M}$ ) is then found theoretically from the formula W (or $\mathrm{M})=\rho \mathrm{V}$, but really practically from the formula $\mathrm{W}=62.45 \mathrm{~V}$, where $\mathrm{V}$ or $\mathrm{M}$ is given in pounds, when $\mathrm{V}$ is given in cubic feet, and $\rho$ is then called the density, and $s$ the specific gravity (the densily relative to water), and it is the specific gravity for which tables are given; but in the metric system W (or M) = $\rho \mathrm{V}=s \mathrm{~V}$, where $\mathrm{W}$ or $\mathrm{M}$ is given in grammes, when $\mathrm{V}$ is given in cubic centimetres, and the density $\rho$, and the specific gravity $s$, are then the same. But turn to the ordinary text-books, and we find these confusing equations-

$$
\mathrm{W}=\mathrm{M}_{\mathrm{s}}=g_{\rho} \mathrm{V}=s \mathrm{~V},
$$

where IV is called the weight, M the mass, $\rho$ the density, and $s$ the specific gravity, followed often by a series of absurd examples on changes of units. 